\title{
Dermatological Manifestations of Down's Syndrome
}

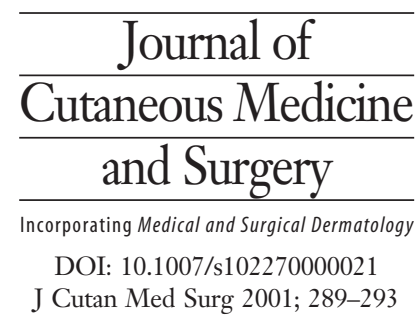

\author{
Benjamin Barankin and Lyn Guenther
}

\begin{abstract}
Background: Down's syndrome (DS) is an extensively researched congenital condition characterized by mental retardation and distinct physical features. The cutaneous manifestations of DS are numerous, yet they seldom receive appropriate attention.

Objective: To review the dermatological conditions associated with DS.

Methods: A review of the medical literature.

Results: DS is associated with an increased incidence of numerous dermatological conditions, some of which may be related to an immunological deficiency.

Conclusion: Along with the importance of understanding the physical and psychosocial aspects of DS, an appreciation of the dermatological manifestations of this condition is integral to comprehensive medical care.
\end{abstract}

\section{Sommaire}

Antécédents: Le syndrome de Down est une affection congénitale qui fait l'objet de nombreuses recherches et qui est caractésisée par un retard mental et des signes physiques particuliers. Ses manifestations cutanées sont nombreuses, mais on leur accorde rarement l'attention qu'elles méritent.

Objectif: Analyser les affections dermatologiques accompagnant le syndrome de Down.

Methodes: Revue de la littérature médicale.

Résultats: Le syndrome de Down est associé à une augmentation de l'incidence d'un grand nombre d'affections dermatologiques dont certaines peuvent être reliées à un déficit immunitaire.

Conclusion: De même qu'il est important de connaître les aspects physiques et psychosociaux du syndrome de Down, il est important de pouvoir en reconnaitre les manifestations dermatologiques, car cela fait partie intégrante des soins médicaux complets.

$\mathrm{D}$ own's Syndrome (DS) is the oldest and most identifiable cause of congenital developmental disability. ${ }^{1}$ Down's syndrome was first described by John Langdon Down in 1865 and the first association between DS and an extra number 21 chromosome was made by Lejeune in $1959 .{ }^{2}$ Children with DS have multiple malformations and mental retardation as a result of the presence of extra genetic material from chromosome $21 .^{3}$

While the phenotype may be variable, some of the more common physical features include hypotonia, epicanthal folds and upward slanting eyes, Brushfield spots, flat nasal bridge, small mouth and ears, large tongue, excess nuchal skin, a single transverse palmar crease, and

The University of Western Ontario, London, Ontario, Canada Online publication: 2 May 2001

Correspondence to: Lyn Guenther, MD, 835 Richmond Street, London, Ontario, Canada N6A 3H7. E-mail: dgue@uwo.ca clinodactyly of the fifth fingers. ${ }^{3,4}$ The degree of mental retardation is variable. There is an increased risk of congenital heart disease $(50 \%)$, seizure disorders $(2.6 \%-$ $8.8 \%)$, atlantoaxial or atlantooccipital instability $(10 \%-$ $30 \%)$, leukemia $(<1 \%)$, deafness $(75 \%)$, serous otitis media $(50 \%-70 \%)$, gastrointestinal atresias $(12 \%)$, cataracts $(15 \%)$, severe refractive errors $(50 \%)$, and hypothyroidism $(15 \%)$ among many other physical and psychosocial difficulties. ${ }^{1-3,5}$

While clinical inspection may be suggestive of the condition, chromosomal analysis is needed to confirm the diagnosis. Down's syndrome occurs in all countries and peoples, with a birth incidence of approximately 1 in 800 live births, making it the most common autosomal chromosomal disorder causing mental retardation. ${ }^{2,4} \mathrm{Al}$ though $80 \%$ of children with DS are born to young mothers, women over 35 years of age are at increased risk of giving birth to a child with DS; the rate at various ma- 
ternal ages is $15-29$ years, $1: 1500 ; 30-34$ years, 1:800; $35-39$ years, $1: 270 ; 40-44$ years, $1: 100$, and $>45$ years, $1: 50 .^{6}$

While the physical and psychosocial aspects of DS have received great attention, the dermatological manifestations have been less of a focus. Interestingly, dermatological disorders do not seem to correlate with other pathological conditions, even those of ectodermal origin (e.g., eyes, teeth) that are also often abnormal in DS.

The high incidence of alopecia areata, vitiligo, and atopic dermatitis may be related to immunological deficiency in thymus-dependent ( $\mathrm{T}$-cell) function which exists in DS. ${ }^{8,9}$ The literature on the humoral or cellular immune system alterations in DS has been met with mixed results. Studies show both reduced number and function of both B- and T-lymphocytes, with thymusdependent function and morphology (T-cell) most consistently affected. ${ }^{2,8,10}$ Phagocytosis also appears to be impaired. ${ }^{10}$ In general, people with DS have a high incidence of mortality caused by infection, ${ }^{5,10}$ increased incidence of malignancies such as leukemia, and are more likely to develop autoimmune conditions such as thyroiditis and alopecia areata. ${ }^{2}$

DS is also associated with accelerated aging and an increased incidence of acne vulgaris, anetoderma, cheilitis, cutis marmorata, elastosis perforans serpiginosa, fissured and geographic tongue, onychomycosis, palmoplantar hyperkeratosis, pityriasis rubra pilaris, psoriasis, seborrheic dermatitis, syringoma, tinea pedis, and xerosis. ${ }^{3,8,11-13}$ Syringoma, alopecia areata, elastosis perforans serpiginosa, and vitiligo usually present in adulthood. ${ }^{3}$

\section{Aging Skin}

There is evidence that people with DS experience accelerated skin aging and a greater effect of sunlight on the skin. ${ }^{14}$ Premature graying of the hair, hair loss, and wrinkling of the skin along with nondermatological aging changes including premature Alzheimer's neuropathology, osteoporosis and osteoarthritis, and premature onset of menopause have been reported. ${ }^{14}$ The mechanism underlying the development of enhanced skin wrinkling remains to be elucidated, although free radical damage may play an important role. ${ }^{14}$

\section{Alopecia Areata}

Alopecia areata (AA) is the most common cause of discrete hair loss in both children and adults. ${ }^{15}$ It ranges in severity from well-circumscribed patches of nonscarring hair loss to total scalp hair loss (alopecia totalis) or total body hair loss (alopecia universalis). The scalp is most commonly affected but the beard and eyebrow areas are often involved as well. ${ }^{16}$ The incidence of $\mathrm{AA}$ is between $6 \%$ and $10 \%$ in the DS population compared with approximately $1.7 \%$ of the general population. ${ }^{2,8,17}$ There is an increased incidence in both sexes; however, unlike the general population in which the rate does not vary with gen- der, it is more common in females with DS $(17.4 \%$ vs. $3.1 \%){ }^{8}$ As in the general population, it may coexist with vitiligo. $^{8}$

\section{Anetoderma}

Anetoderma is a rare condition consisting of circumscribed areas of flaccid skin often with fat herniation. Histologically, it is characterized by a lack of elastic fibers. ${ }^{18}$ In DS, it has been reported secondary to folliculitis. ${ }^{18}$ Anetoderma has also been reported in association with alopecia areata, vitiligo, and hypothyroidism, conditions seen with increased incidence in DS. ${ }^{19}$

\section{Atopic Dermatitis}

Atopic dermatitis usually begins early in life and is characterized by an intensely pruritic eczematous eruption that is itchy, recurrent, and symmetric. ${ }^{20}$ While some studies have suggested an increased prevalence of $>50 \%$ of atopic dermatitis in patients with $\mathrm{DS},{ }^{8,21}$ others have shown it to be decreased. Using the criteria of Hanifin and Rajka, Schepis et al. ${ }^{22}$ noted only a $3 \%$ prevalence. The lifetime prevalence in non-DS children aged 3-11 years has been estimated to be $20 \% .^{23}$

\section{Cheilitis}

Cheilitis occurs in approximately 6\% of people with DS and is more common in males. ${ }^{1,11,13}$ The DS infant usually has normal lips, but with time there is whitening and thickening of the mucous membrane. ${ }^{11}$ Later, vertical fissures occur followed by enlargement of the lips, scaling, and crusting. Although the fissures are deep, they heal at times leaving prominent vertical lines. ${ }^{11}$ The hypertrophy, scaling, crusting, and fissuring noted in the lips of DS patients are thought to be the result of trauma or chronic low-grade infection, but the true cause remains unknown. ${ }^{2,11,21}$

\section{Cutis Marmorata}

Cutis Marmorata $(\mathrm{CM})$ is a transient, reticulated vascular pattern on the skin of extremities (Fig. 1). ${ }^{8}$ The frequency of this condition is between $8 \%$ (age range 12 $48)^{8}$ and $13 \%$ (mean age 2 years 10 months) ${ }^{13}$ of patients with DS. In the general population, CM is especially common in very young infants, but less common in older individuals. ${ }^{24}$ Cutis Marmorata and acrocyanosis are likely more common in DS past infancy because of poor peripheral circulation and increased incidence of congenital heart disease. ${ }^{21}$

\section{Elastosis Perforans Serpiginosa (EPS)}

In this uncommon transepidermal elimination disorder, thickened elastic fibers are extruded through epidermal channels producing keratotic papules which often coalesce to form a serpiginous or arcuate pattern (Fig. 2). ${ }^{4,21}$ 
FIGURE 1 A child with cutis marmorata of the arm.

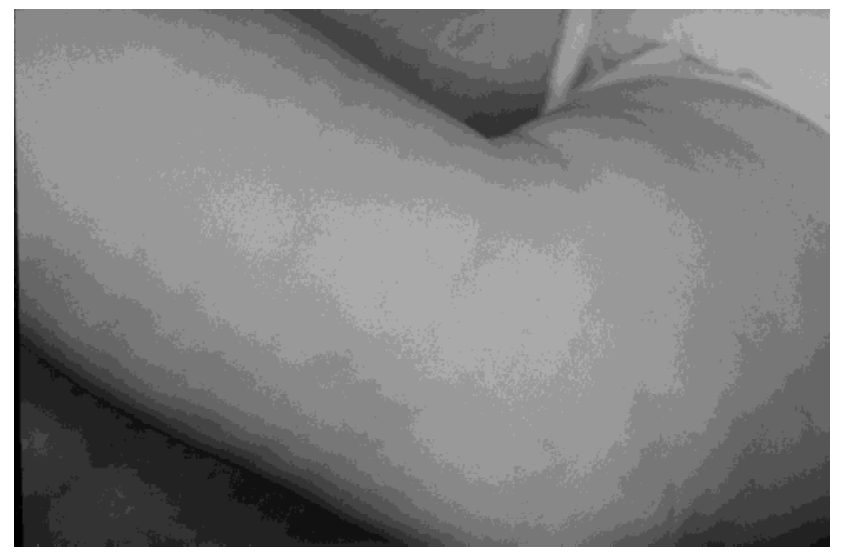

FIGURE 2 A child with Down's syndrome with elastosis perforans serpiginosa (EPS).

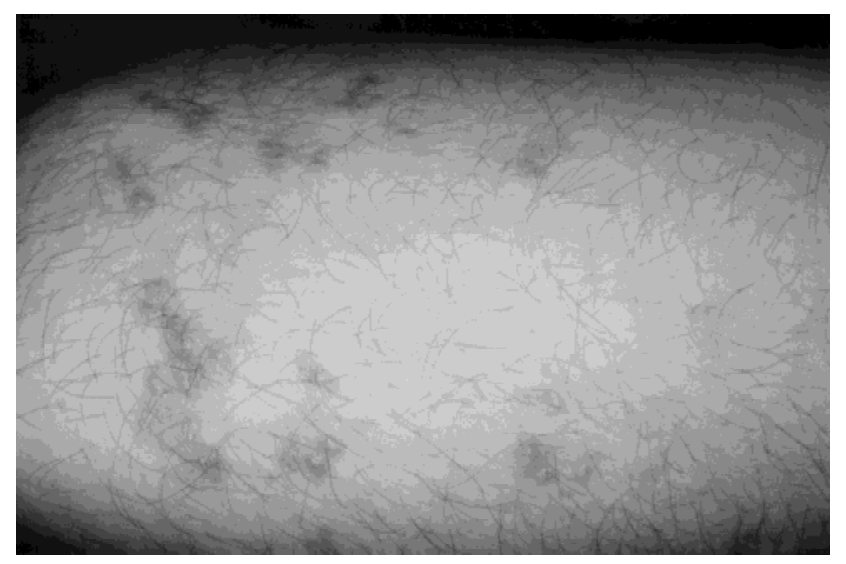

EPS was first reported by Lutz in 1953 as keratosis folliculitis serpiginosa. ${ }^{25}$ It usually has an onset in the second decade, with males four times more likely to have it than females. $^{4,21}$ The natural progression of EPS can produce linear and retiform scars. ${ }^{12}$ Approximately 30\% have an associated connective tissue disorder including Down's syndrome, Ehlers-Danlos syndrome, cutis laxa, pseudoxanthoma elasticum, Marfan's syndrome, osteogenesis imperfecta, Rothmund-Thompson syndrome, acrogeria, morphea, and systemic sclerosis. ${ }^{26}$

The association with DS has been recognized as early as $1955 .^{4}$ While some studies have found it to be more common in DS, ${ }^{27,28}$ others suggest no association. ${ }^{9} \mathrm{Re}-$ active perforating collagenosis (RPC), another perforating disorder, has also been reported in DS. ${ }^{4,29}$

As opposed to the idiopathic form of EPS which is usually localized, DS EPS has a more extensive distribution of lesions and has a longer duration ( $\geq 10$ years vs. 5 years). ${ }^{4,21}$

\section{Fissured Tongue}

The frequency of occurrence of deep surface furrows on the tongue in DS patients has varied from $20 \%$ to as high as $95 \%,{ }^{2,3}$ while it is found in only $2 \%-5 \%$ of the general population. Most cases are asymptomatic. There is a strong tendency for a superimposed geographic condition to develop in the fissured tongue. ${ }^{2}$

\section{Folliculitis}

Folliculitis is the inflammation of hair follicles. In DS, there is a $10 \%$ incidence of folliculitis, ${ }^{7}$ which predominantly involves the upper back, chest, and shoulders. ${ }^{30}$ Finn et al. ${ }^{31}$ noted a distinctive follicular dermatosis in $45 \%$ of male patients with DS which they speculated was a follicular variety of seborrheic dermatitis. This description is, in fact, consistent with the diagnosis of Malassezia folliculitis. ${ }^{30}$ The susceptibility of DS patients to folliculitis is probably related to some form of immunological deficit. $^{30}$

\section{Furunculosis (Boils)}

Pain, redness, and swelling accompany boils, skin infections (Stapbylococcal or Streptococcal) originating in the pilosebaceus unit. ${ }^{32}$ Recurrent furunculosis of the thighs is common and troublesome in patients with DS. ${ }^{9}$ There is a $26 \%$ reported incidence of scarring trunk furunculosis. ${ }^{7}$

\section{Geographic Tongue}

This is an inflammatory disorder on the tongue characterized by many areas of loss and regrowth of the filiform papillae which gives a maplike appearance to the tongue. ${ }^{32}$ The frequency of this disorder in patients with DS has been shown to be $11 \%$, while the general population rate is only $1 \%-2 \% .{ }^{13}$ Approximately $40 \%$ of patients with geographic tongue also have fissured tongue. ${ }^{4}$

\section{Milia-Like Idiopathic Calcinosis Cutis (MICC)}

In this condition, patients present in childhood or early adulthood with multiple, asymptomatic flesh or yellow nodules which often release a granular chalky material. ${ }^{33}$ MICC, like elastosis perforans serpiginosa and some cases of calcinosis cutis, shows perforation and has been reported in DS. ${ }^{34}$

\section{Norwegian (Crusted) Scabies}

Used to describe an overwhelming scabies infestation, lesions tend to involve the hands and feet with asymptomatic crusting rather than the typical inflammatory papules. $^{20}$ This condition is more commonly found in patients with DS and may be related to the immunologic dysfunction seen in DS. ${ }^{2,20}$ Norwegian scabies is also seen more frequently in patients with immunodeficiency secondary to HIV infection. ${ }^{35}$

\section{Onychomycosis}

Onychomycosis is any fungal infection of the nail. In the general population, the incidence of onychomycosis is re- 
ported to be $20 \%,{ }^{36}$ whereas it is more than $50 \%$ in patients with DS. ${ }^{8,21}$ Immunosuppression is considered a risk factor for this condition. ${ }^{24}$

\section{Palmoplantar Hyperkeratosis}

In this condition, keratin on the palms and soles is thickened. The condition onsets after age 5 months, with prevalence in DS patients of about $40 \% .{ }^{13}$ The prevalence increases to $75 \%$ in DS patients above 5 years of age. ${ }^{13}$ Although dermatological findings such as dry skin, ichthyosis-like lesions, and palmoplantar hyperkeratosis in DS patients have been attributed to a possible vitamin A deficiency, ${ }^{4}$ a study by Ercis et. $\mathrm{al}^{13}$ found no such association.

\section{Pityriasis Rubra Pilaris}

Pityriasis rubra pilaris (PRP) is a rare, chronic, papulosquamous disorder of unknown etiology characterized by thick, smooth, yellow palms and soles and erythroderma. ${ }^{20}$ This condition has been described in patients with DS but remains a rare occurrence. ${ }^{37,38}$ Severe forms of PRP may be unmasked, precipitated, or otherwise associated with HIV, another immunodeficient state. ${ }^{20,39,40}$

\section{Psoriasis}

The incidence of psoriasis in the general population is $1 \%-3 \%,{ }^{20}$ while it has been noted to be $0.5 \%{ }^{8}-8 \%{ }^{7}$ in patients with DS. Psoriasis in the patient with DS again may be related to an immunocompromised state, and, similarly, psoriasis, particularly severe psoriasis, may be one of the presenting signs of acquired immunodeficiency syndrome (AIDS). ${ }^{20,35}$ Although psoriasis may be exacerbated by AIDS and severe psoriasis in an HIV positive patient is a poor prognostic factor, there is, in fact, no increased incidence of psoriasis in patients infected with $\mathrm{HIV}^{35}$

\section{Seborrheic Dermatitis}

Seborrheic dermatitis is a common chronic condition typified by erythema and yellow-brown scales on the scalp, face (particularly the sides of the nose, in the eyelashes and eyebrows, or in and around the ear), and trunk. ${ }^{15}$ The $30 \%-36 \%$ reported incidence in patients with DS is higher than that in the general population $(2-5 \%) .{ }^{8,13}$ The higher incidence appears to be related to the immunocompromised state of these patients. ${ }^{13}$ Seborrheic dermatitis is also more common in patients with HIV infection, another condition of immunodeficiency (up to $85 \%$ affected). ${ }^{41}$

\section{Syringoma}

Syringomas are benign appendageal tumors of eccrine origin, most typically found in the periorbital region. ${ }^{42}$ They are round or oval small $(0.50-1.5 \mathrm{~mm})$ dermal pap- ules, flesh colored or with a yellow or brown tint. ${ }^{9,42}$ They often develop in adolescence, with further lesions developing later in life, and they are twice as common in women. ${ }^{8,42,43}$ Plaque-type and eruptive variants have been reported. ${ }^{42,43}$

Syringomas are more common in patients with DS and twice as common in female DS patients. ${ }^{2}$ The frequency in DS has been estimated at $18 \%,{ }^{42}$ although one study found a frequency of $39 \%$ (58\% of females and $27 \%$ of males). ${ }^{8}$

\section{Tinea Pedis}

Tinea pedis, or "athlete's foot," is a fungal infection of the feet, the most common area infected by dermatophytes. ${ }^{20}$ The reported increased incidence of tinea pedis in DS $(76.6 \% \text { in one study })^{8}$ may be related to institutionalization. Other dermatophytic infections such as severe onychomycosis and tinea corporis are commonly seen in older institutionalized patients with DS. ${ }^{44}$

\section{Transverse Palmar Crease/Simian Crease}

A single crease on one or both palms is called a simian crease, and it is evident in $40 \%-50 \%$ of DS patients. ${ }^{4,13} \mathrm{It}$ is one of the many features of Down's syndrome but is also observed in several other syndromes, namely, trisomy 13, Cornelia de Lange's syndrome, Seckel's syndrome, and cri du chat syndrome. ${ }^{4}$

\section{Vitiligo}

Vitiligo is caused by the loss of melanocytes from the skin and manifests itself as white patches. Vitiligo may be associated with autoimmune diseases, which may explain its marginally higher incidence (2\%) in the DS population. ${ }^{4,8,15}$

\section{Xerosis}

Xerosis, or dry skin, has been reported in from $9.8 \%{ }^{13}$ (age range 2 months-25 years; mean age of 2 years 10 months; increased to $75 \%$ incidence above 5 years of age) $85 \%^{8}$ (age range $12-48$ years) of patients with DS. In DS, the skin in infancy is usually soft, but soon becomes dry, thick, and rough with patchy lichenification. ${ }^{9}$

\section{Conclusions}

People with DS form the largest group of persons with intellectual disability. Enhanced knowledge regarding comorbidity should improve the quality of life of people with DS who often have difficulty communicating their signs and symptoms. ${ }^{10}$ Good medical care has been shown to not only improve their life expectancy but also to help maintain patients in active vocational and group-living programs. ${ }^{45,46}$ Part of this comprehensive care involves an understanding and appreciation of the dermatological 
manifestations of DS and how they impact both the medical and psychological health of the patient.

\section{References}

1. Tolkin J, Meschino WS. The primary care of the child with Down syndrome. Contemp Pediatr 1994; 12-22.

2. Cooley WC, Graham Jr. JM. Down syndrome: An update and review for the primary pediatrician. Clin Pediatr 1991; 30(4):233-253.

3. Seashore MR. Health supervision for children with Down syndrome. Pediatrics 1994; 93(5):855-859.

4. Fitzpatrick TB, Eisen AZ, Wolff K, et al., eds. Dermatology in general medicine, 4th ed. New York: McGraw-Hill, 1993

5. Pueschel SM. Clinical aspects of Down syndrome from infancy to adulthood. Am J Med Genet 1990; 7(suppl):52-56.

6. Smith D, Jones K, eds. Recognizable patterns of human malformation, 3rd ed. Philadelphia: W.B. Saunders, 1982.

7. Polenghi MM, Plattoni F, Orsini GB, et al. Dermatologic disorders in Down syndrome (abstract). Am J Med Genet 1990; 7 (suppl):324.

8. Carter DM, Jegasothy BV. Alopecia areata and Down syndrome. Arch Dermatol 1976; 112:1397-1399.

9. Howells G. Down's syndrome and the general practitioner. J R Coll Gen Pract 1989; 39:470-475.

10. Van Schrojensterin Lantman-de Valk HMJ, Haveman MJ, Crebolder HFJM. Comorbidity in people with Down's syndrome: a criteria-based analysis. J Intellect Disabil Res 1996; 40(5):385-399.

11. Butterworth T, Leoni EP, Beerman H, et al. Cheilitis of mongolism. J Invest Dermatol 1960; 35:347-352.

12. Rasmussen JE. Disseminated elastosis perforans serpiginosa in four Mongoloids. Br J Dermatol 1972; 86:9-13.

13. Ercis M, Balci S, Atakan N. Dermatologic manifestations of 71 Down syndrome children admitted to a clinical genetics unit. Clin Genet 1996; 50:317-320.

14. Brugge KL, Grove GL, Clopton P, et al. Evidence for accelerated skin wrinkling among developmentally delayed individuals with Down's syndrome. Mech Ageing Dev 1993; 70:213-225.

15. Ashton R, Leppard B. Differential diagnosis in dermatology, 2nd ed. Oxford: Radcliffe Medical Press, 1993.

16. Frankel DH. Field guide to clinical dermatology. Philadelphia: Lippincott Williams \& Wilkins, 1999.

17. Safavi KH, Muller SA, Suman VJ, et al. Incidence of alopecia areata in Olmsted County, Minnesota, 1975 through 1989. Mayo Clin Proc 1995; 70:628-633.

18. Schepis C, Siragusa M. Secondary anetoderma in people with Down's syndrome. Acta Derm Venereol 1999; 79(3):245.

19. Hodak E, Shamai-Lubovitz O, David M, et al. Immunologic abnormalities associated with primary anetoderma. Arch Dermatol 1992; 128(6):799-803.

20. Habif TP. Clinical dermatology. St. Louis: Mosby-Year Book, 1996

21. Scherbenske JM, Benson PM, Rotchford JP, et al. Cutaneous and ocular manifestations of Down syndrome. J Am Acad Dermatol 1990; 22:933-938.

22. Schepis C, Barone C, Siragusa M, et al. Prevalence of atopic der- matitis in patients with Down syndrome: A clinical survey. J Am Acad Dermatol 1997; 36:1019-1021.

23. Kay J, Gawkrodger DJ, Mortimer MJ, et al. The prevalence of childhood atopic eczema in a general population. J Am Acad Dermatol 1994; 30(1):35-39.

24. Sams WM Jr, Lynch PJ. Principles and practice of dermatology, 2nd ed. New York: Churchill Livingstone, 1996.

25. Lutz W. Keratosis folliculitis serpiginosa. Dermatologica 1953; 106:318-320.

26. Patterson JW. The perforating disorders. J Am Acad Dermatol 1984; 10:561-581.

27. Haber H. Miescher's Elastoma. Br J Dermatol 1959; 71:85-87.

28. Mehregan AH. Elastosis perforans serpiginosa, a review of the literature and report of 11 cases. Arch Dermatol 1968; 97(4):381-393.

29. De Berker DAR, Wilson CL, Millard PR. Reactive perforating collagenosis and Down's syndrome. Br J Dermatol 1992; 126:71-73.

30. Kavanagh GM, Leeming JP, Marshman GM, et al. Folliculitis in Down's syndrome. Br J Dermatol 1993; 129:696-699.

31. Finn OA, Grant PW, McCallum DI, et al. A singular dermatosis of mongols. Arch Dermatol 1978; 114:1493-1494.

32. Mosby's Dictionary, 5th ed. St. Louis: Mosby-Year Book, 1998.

33. McKee PH. Pathology of the skin, 2nd ed. London: Mosby-Wolfe, 1996.

34. Schepis C, Siragusa M, Palazzo R, et al. Milia-like idiopathic calcinosis cutis: An unusual dermatosis associated with Down syndrome. Br J Dermatol 1996; 134:143-146.

35. Dover JS, Johnson RA. Cutaneous manifestations of human immunodeficiency virus infection. Arch Dermatol 1991; 127:1549-1559.

36. Fitzpatrick TB, Johnson RA, Wolff K, et al. Color atlas and synopsis of clinical dermatology, 3rd ed. McGraw-Hill, New York, pp 1997.

37. Hazini AR, Rongioletti F, Rebora A. Pityriasis rubra pilaris and vitiligo in Down's syndrome. Clin Exp Dermatol 1988; 13:334-335.

38. Holden CA, Curley RK. Down's syndrome and pityriasis rubra pilaris. Clin Exp Dermatol 1989; 14:332.

39. Miralles ES, Nunez M, De Las Heras ME, et al. Pityriasis rubra pilaris and human immunodeficiency virus infection. Br J Dermatol 1995; 133:990-993.

40. Sanchez-Regana M, Fuentes CG, Creus L, et al. Pityriasis rubra pilaris and HIV infection: a part of the spectrum of HIV-associated follicular syndrome. Br J Dermatol 1995; 133:814-821.

41. Mathes BM, Denglass MC. Seborrheic dermatitis in patients with acquired immunodeficiency syndrome. J Am Acad Dermatol 1985; 13:947.

42. Butterworth T, Strean L, Beerman H. Syringoma and mongolism. Arch Dermatol 1964; 90:483-487.

43. Urban CD, Cannon JR, Cole RD. Eruptive syringomas in Down's syndrome. Arch Dermatol 1981; 117:374-375.

44. Moschella SL, Hurley HJ, eds. Dermatology, vol 2. Philadelphia: W.B. Saunders, 1985.

45. Serra A, Neri G. Trisomy 21: conference report and 1990 update. Am J Med Genet 1990; 7(Suppl):11-19.

46. Carr J. Annotation: Long term outcome for people with Down's syndrome. J Child Psychol Psychiat 1994; 35:425-439. 